\title{
INTERLOCUÇÕES SOBRE CURRÍCULO E A IMPLEMENTAÇÃO DA BNCC DE GEOGRAFIA: BUSCANDO PEDAGOGIAS DECOLONIAIS PARA O CONTEXTO AMAZÔNICO
}

\author{
Vanessa Lessio DINIZ \\ Osmar Oliveira de MOURA ${ }^{\text {ii }}$
}

\begin{abstract}
RESUMO
O presente artigo tem como propósito contribuir para as discussões sobre a implementação da Base Nacional Comum Curricular (BNCC), investigando indícios da colonialidade presente nas interlocuções vivenciadas no Projeto de Extensão "Interlocuções sobre a implementação da BNCC de Geografia: construindo práticas educativas regionais". Com base na perspectiva pós-crítica e pós-estruturalista da Teoria do Discurso de Ernesto Laclau e Chantal Mouffe, compreendemos que a elaboração e a implementação da BNCC estão carregadas de disputas discursivas entre contextos políticos, concepções institucionais e atores sociais envolvidos nesse processo. Metodologicamente, a partir da análise dos enunciados de nossas interlocutoras, constatamos que as pedagogias decoloniais podem construir outras formas de representações, sentidos e saberes geográficos diante dos conteúdos programáticos prescritos nesse documento curricular.
\end{abstract}

PALAVRAS-CHAVE: Documentos curriculares; Geografia escolar; Interlocuções de saberes; Práticas educativas; Tocantins.

\section{CURRICULUM AND IMPLEMENTATION OF THE GEOGRAPHY NCCB IN THE AMAZON CONTEXT: INTERLOCUTIONS FOR THE CONSTRUCTION OF DECOLONIAL PEDAGOGIES}

\begin{abstract}
The purpose of this article is to contribute to discussions on the implementation of the National Common Curricular Base (NCCB), by investigating evidence of coloniality present in the interlocutions experienced in the Extension Project "Interlocutions on the implementation of the NCCB in Geography: building regional educational practices". Based on the post-critical and post-structuralist perspective of Ernesto Laclau and Chantal Mouffe's Theory of Discourse, we understand that the design and implementation of the NCCB are fraught with discursive disputes between political contexts, institutional conceptions and social actors involved in this process. Methodologically, from the analysis of the statements of our interlocutors, we found that decolonial pedagogies can build new forms of representations, meanings and geographical knowledge in view of the syllabus prescribed in this curricular document.
\end{abstract}

KEYWORDS: Curricular documents; School geography; Interlocutions of knowledge; Educational practices; Tocantins.

\footnotetext{
${ }^{\text {i }}$ Doutorado em Geografia pelo Instituto de Geociências da Universidade Estadual de Campinas (Unicamp). Professora do curso de Licenciatura em Geografia da Universidade Federal do Tocantins (UFT) - Campus Araguaína. E-mail: vanessalessiodiniz@gmail.com.

ii Graduando em Geografia pela Universidade Federal do Tocantins (UFT), Campus de Araguaína. Bolsista do Programa Institucional de Bolsas de Extensão Pibex/UFT com o Projeto "Interlocuções sobre a implementação da BNCC de Geografia: construindo práticas educativas regionais". E-mail: osmaroliveirademoura@ gmail.com. 


\title{
CURRÍCULO Y LA IMPLEMENTACIÓN DE LA GEOGRAFÍA BCCN EN EL CONTEXTO AMAZÓNICO: INTERLOCUCIONES PARA LA CONSTRUCCIÓN DE PEDAGOGÍAS DECOLONIALES
}

\begin{abstract}
RESUMEN
El propósito de este artículo es contribuir a las discusiones sobre la implementación de la Base Curricular Común Nacional (BCCN), investigando evidencias de colonialidad presentes en las interlocuciones vividas en el Proyecto de Extensión "Interlocuciones sobre la implementación del BCCN en Geografia: construyendo prácticas educativas regionales". A partir de la perspectiva poscrítica y postestructuralista de la Teoría del Discurso de Ernesto Laclau y Chantal Mouffe, entendemos que el diseño y la implementación del BCCN están plagados de disputas discursivas entre contextos políticos, concepciones institucionales y actores sociales involucrados en este proceso. Metodológicamente, a partir del análisis de los planteamientos de nuestros interlocutores, encontramos que las pedagogías descoloniales pueden construir nuevas formas de representaciones, significados y conocimientos geográficos a la luz del temario prescrito en este documento curricular.
\end{abstract}

PALABRAS CLAVE: Documentos curriculares; Geografía escolar; Interlocuciones de conocimientos; Prácticas educativas; Tocantins.

\section{INTRODUÇÃO}

O projeto de uma educação com base única e padronizada no Brasil remete a diferentes momentos históricos, marcados por distintas situações políticas e socioeconômicas pelas quais já passaram nossa sociedade, e as tendências para a educação brasileira não são desconexas dos momentos mais marcantes do cenário histórico nacional e mundial. Barbosa, Diniz e Paulino (2020, p. 13), em trabalho recente sobre os conflitos e as resistências entre o global e o local na produção e implementação de documentos curriculares, nos alertam de que vivemos em tempos de globalização, isto é, tempos em que a ordem global busca impor, a todos os lugares, uma única racionalidade sobre as esferas política, econômica, cultural e também educacional. Afirmam que "vivemos uma internacionalização das políticas educacionais, em que agências internacionais, financeiras ou não, formulam recomendações sobre políticas públicas para países emergentes ou em desenvolvimento".

Com a redemocratização do Brasil, no final da década de 1980, presenciamos mudanças na educação brasileira, sobretudo com a promulgação da Constituição Federal de 1988, quando se garantiu, "dentre outros avanços, o acolhimento de uma concepção ampla de educação, sua inscrição como direito social inalienável, e a vinculação constitucional de percentuais mínimos dos orçamentos públicos" (PEREIRA, 2017, p. 02). No artigo nº 210 da Constituição (BRASIL, 
1988), encontramos referência à fixação de "conteúdos mínimos" para a educação nacional, no entanto, esse termo foi alterado para "base nacional comum" pela Lei de Diretrizes e Bases (LDB) nº 9.394, de 20 de dezembro de 1996 (BRASIL, 2017). Entende-se assim que não há novidade na motivação e prescrição de um currículo comum, embora nem sempre haja consenso sobre a conveniência dessa prescrição (MACEDO, 2015) e principalmente sobre sua operacionalização em um território marcado pelas desigualdades regionais.

É nítido que a apresentação e a ênfase dada aos marcos legais ${ }^{1}$ que culminaram com a elaboração e homologação final da BNCC são utilizadas como estratégia para se reafirmar a importância e a necessidade de um projeto de base curricular prescritivo de forma comum para todo território brasileiro, trazendo como pano de fundo o discurso da melhoria na qualidade da educação, porém, "ao se construir tal projeto, pouco se problematiza a noção de qualidade da educação. A qualidade da educação tende a ser reduzida a uma vaga noção de qualidade de ensino, de assimilação de conteúdos, ao cumprimento de expectativas de aprendizagem" (LOPES, 2018, p. 26). A partir de outra perspectiva, Girotto (2017) apresenta a articulação de um conjunto de políticas neoliberais para a Educação e para o Estado brasileiro construídas por órgãos internacionais (em especial, o Banco Mundial) na década de 1990 na qual os Parâmetros Curriculares Nacionais (PCNs) em 1997 e atualmente a BNCC representam mais uma etapa desse movimento de reforma neoliberal do Estado e precisam, portanto, ser interpretados nessa relação.

A BNCC, aprovada pelo Conselho Nacional de Educação (CNE) com última versão homologada pelo Ministério da Educação (MEC) em 14 de dezembro de 2018, é o atual documento direcionador dos currículos escolares do Estado brasileiro. Possui caráter normativo [obrigatório] e prescritivo, estabelecendo o conjunto de "aprendizagens essenciais" a serem trabalhadas com os estudantes ao longo das etapas e modalidades de ensino da educação básica (BRASIL, 2018), como padrões a serem seguidos. Consideramos, assim, a BNCC um documento curricular, uma vez que a Base reforça o controle e a prescrição do conhecimento a ser ensinado, além do modo de fazer nas produções curriculares.

Sua construção passou por inúmeros processos de debates e críticas, levando em consideração a produção de uma política curricular, cuja magnitude é de escala nacional e imperativa (GIROTTO, 2017; AGUIAR; DOURADO, 2018; CURY; REIS; ZANARDI, 2018). A construção da Base foi iniciada em junho de 2015, após a definição da primeira comissão de 
Programa de Pós-Graduação em Educação: Currículo

especialistas responsáveis por sua escrita. Podemos observar brevemente o contexto de produção da Base de Geografia apresentado na Figura 1.

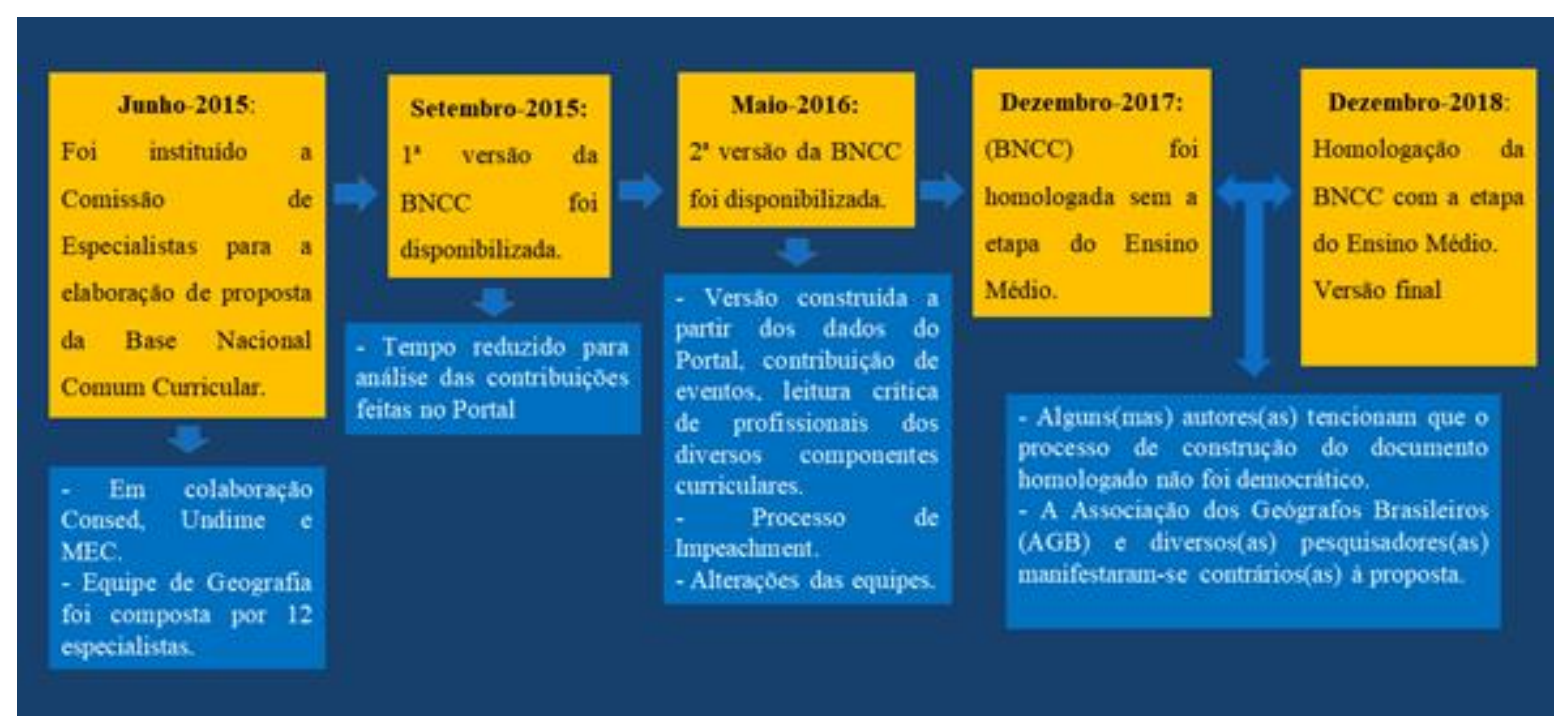

Figura 1 - Esquema do contexto de produção da BNCC de Geografia (2015-2018)

Fonte: Organizado pelos autores a partir do Portal do MEC; Valladares et al. (2016); AGB (2017); Aguiar e Dourado (2018).

No ano de 2020 - embora marcado por uma pandemia provocada pelo coronavírus SARS-CoV-2, o COVID-19 - está prevista a implementação da BNCC em todas as escolas brasileiras. Embora muito já tenha sido discutido sobre a produção desse novo documento curricular, a operacionalização de sua implementação in loco ainda gera em gestores(as) e professores(as) da educação básica, assim como em pesquisadores(as) da área, muitas dúvidas, incertezas e pouco consenso sobre sua utilização. Constata-se que o documento foi finalizado e homologado durante um cenário político controverso, no entanto, sendo precondição para os nossos debates sobre a proposta da área de Ciências Humanas (Ensino Fundamental) e Ciências Humanas e Sociais Aplicadas (Ensino Médio), em especial para o nosso debate sobre a Geografia escolar presente nesse documento, destacando sua articulação com um projeto social mais amplo e que envolve uma concepção de sujeito e de educação a ser fomentada em detrimento de tantas outras possíveis (GIROTTO, 2017).

Concordamos com Lopes (2018) quando a autora discute que não há o que se possa chamar de uma parte curricular nacional ou global pura e um contexto local puro, sem inter-relações entre os sentidos dessas supostas partes. Mesmo o documento destacando a necessidade de uma parte diversificada, exigida pelas características regionais e locais da 
sociedade e da cultura dos educandos, é evidente a dificuldade de se trabalhar diferentes representações frente às diversidades sócio-territoriais e as identidades múltiplas dos povos brasileiros, como o cotidiano e os saberes tocantinenses e amazônicos ${ }^{2}$, por exemplo, que podem permanecer silenciados nos processos de implementação da BNCC. Além disso, observa-se a dificuldade na leitura e na compreensão das "competências e habilidades" exigidas nesse documento curricular.

Nessa direção, as discussões e reflexões presentes neste artigo emergem das interlocuções, ou seja, das conversas trocadas e dos diálogos vivenciados em ações do Projeto de Extensão "Interlocuções sobre a implementação da BNCC de Geografia: construindo práticas educativas regionais" ", desenvolvido no curso de licenciatura em Geografia (campusAraguaína), da Universidade Federal do Tocantins (UFT). Esse projeto tem como principal objetivo elaborar práticas educativas de forma colaborativa entre professores(as) das escolas públicas tocantinenses e futuros(as) professores(as) (licenciandos(as)) de Geografia, partindo do entrelaçamento entre os conhecimentos geográficos presentes na Base Nacional Comum Curricular (BNCC) e o contexto regional (amazônico), de modo a incentivar a construção de pedagogias decoloniais como enfrentamento aos diferentes processos, e consequentemente, aos diferentes desafios vivenciados na/para a implementação desse documento curricular nacional.

Com base na racionalidade moderna/colonial, os discursos hegemônicos do homem branco/civilizado/cristão/heterossexual e do patriarcado continuam presentes nos currículos, e consequentemente, na prática docente e no ambiente escolar. Podemos dizer que no processo de construir uma proposta curricular decolonial existe a necessidade de transcender o lugar comum que ignora os impactos assimétricos de poder, em relação aos regimes de representação e autorização da fala dos sujeitos esculpidos nos currículos escolares.

Dessa forma, o presente artigo tem como objetivo contribuir para as discussões sobre a implementação da Base Nacional Comum Curricular (BNCC), investigando indícios da colonialidade presente nas interlocuções vivenciadas no Projeto de Extensão anteriormente mencionado, buscando, por meio dos espaços de trocas de saberes, a construção de pedagogias decoloniais. Para tanto, estruturamos o texto em duas seções. Na primeira, apresentamos uma discussão na perspectiva pós-crítica e pós-estruturalista, que considera o currículo uma construção sócio-discursiva. Além disso, discutimos as contribuições das teorias pós-coloniais e dos estudos decoloniais para analisarmos a produção e implementação de documentos 
curriculares. Posteriormente, na segunda seção, analisamos os enunciados de nossas interlocutoras, participantes de um ciclo de oficinas realizado nos meses de junho e julho de 2020, buscando identificar indícios de colonialidade nas discussões sobre currículo e sobre a implementação da BNCC de Geografia. Por fim, realizamos breves apontamentos sobre a importância dos espaços de diálogo e troca de saberes na construção de outras formas de representações, sentidos e saberes geográficos diante dos conteúdos programáticos prescritos nesse documento curricular.

\section{OS ESTUDOS SOBRE CURRÍCULO NUMA PERSPECTIVA SÓCIO-DISCURSIVA E DECOLONIAL}

Tem-se acentuado, nos últimos anos, a influência das perspectivas discursivas póscrítica e pós-estruturalista nas pesquisas que analisam o contexto de produção de documentos curriculares. Longe de ignorarem os processos de dominação existentes nas diferentes relações sociais, inclusive na de classe, essas perspectivas passaram a fornecer um olhar mais complexo sobre a concepção de identidade cultural e social, permitindo assim a compreensão política do currículo para além das questões de classes sociais e das atividades econômicas do Estado (LOPES; MACEDO, 2011; SILVA, 2015).

Pretendendo compreender a complexidade dos processos de misturas e de contatos entre grupos, nações e a pluralidade que se dá contemporaneamente, utilizaremos a Teoria do Discurso proposta por Ernesto Laclau e Chantal Mouffe (LACLAU, 2011; LACLAU; MOUFFE, 2015; MENDONÇA; RODRIGUES, 2014) como suporte teórico-metodológico no direcionamento de nossas discussões. Essa teoria permite pensarmos a sociedade numa concepção relacional e discursiva, evitando o reducionismo, o determinismo e o existencialismo, utilizando-se de uma constelação de categorias ${ }^{4}$ para explicar fenômenos e eventos sociais.

O contexto educacional de um país recebe múltiplas influências na construção dos seus currículos, as quais refletem o jogo de forças entre diferentes sujeitos sociais, como, por exemplo, as negociações entre o Governo e a sociedade, e também as imposições de órgãos externos financiadores de políticas para a educação. Ou seja, o currículo é uma construção social, podendo ser entendido como uma arena de todos os tipos de mudanças, interesses e relações de dominação (GOODSON, 1995). Assim, as propostas curriculares ancoradas nas 
disciplinas escolares deixam sempre à mostra diferentes dimensões de Estado, como a econômica, a política e a cultural, representando os interesses substanciais de uma hegemonia política - que sempre será contingencial e provisória (LOPES, 2011).

Essa Teoria do Discurso recentemente vem sustentando alguns estudos curriculares e pode permitir a identificação de contradições com uma lógica reprodutiva, pois "busca superar a separação entre a proposta [curricular] e sua implementação, bem como entre estrutura e agência, por meio de abordagens discursivas" (LOPES; MACEDO, 2011, p. 235). Permite romper com abordagens que apenas enfatizam a verticalização dos movimentos de produção, dando destaque aos processos de tradução ${ }^{5}$ que as políticas, concebidas como discursos, sofrem nos diferentes contextos de produção e de prática curricular (COSTA; PEREIRA, 2013). Essa abordagem favorece a indagação sobre as relações entre contextos de produção de currículos, sujeitos produtores, contextos de apropriação curricular e sujeitos presentes nos currículos, revelando também o quanto a elaboração e implementação de um currículo pode ser complexa e ir muito além da proposta curricular que o sustenta.

Os processos de significação discursiva acontecem por meio de um sistema articulatório de cadeias de diferença e de equivalência, que disputam sentidos criados no movimento de luta política. Diferentes demandas, que estão dispersas no campo da discursividade, são ordenadas em uma cadeia de equivalência. Nessa perspectiva discursiva, entendemos que

o ordenamento das demandas políticas acontece em função de um exterior constitutivo, uma diferença interpretada como ameaça comum a ser combatida, um outro opressor. Tal momento possibilita que demandas diferenciadas de um meio social possam abrir mão de seus conteúdos particulares para se incorporarem em uma articulação que aspira à hegemonia (COSTA; PEREIRA, 2013, p. 296).

Segundo Laclau (2011), essa hegemonia ${ }^{6}$ consiste em um processo permanente de disputa, cujo objetivo é a fixação de determinados significados particulares, desejando que eles possam representar a totalidade. Entretanto, a fixação desses sentidos será sempre contingencial e provisória, e acontecerá a partir de determinadas condições específicas. A constituição de uma cadeia de equivalência para a formação de um discurso hegemônico se torna possível quando a articulação de demandas diferenciais se dá em torno de pontos nodais, ou seja, pontos de interseções contra os quais as identidades opostas a eles se unem, gerando a sensação de solidariedade (LOPES, 2011). Para Laclau, o "discurso é uma categoria que une palavras e 
ações, que tem natureza material e não mental e/ou ideal. Discurso é prática - daí a noção de prática discursiva" (MENDONÇA; RODRIGUES, 2014, p. 49).

Dessa forma, compreendemos que o discurso é um movimento constante de disputa de significação e se torna hegemônico quando um ponto nodal fecha a cadeia de significação em uma dada formação discursiva; quando um ou mais discursos particulares passam a se expressar como discurso universal. Contudo, neste artigo, olharemos para o currículo como "um processo de produção de sentidos, sempre híbridos, que nunca cessa e que, portanto, é incapaz de produzir identidades [monolíticas]. O que ele produz é diferença pura, adiamento do sentido e, portanto, necessidade incessante de significação" (LOPES; MACEDO, 2011, p. 227). O currículo, em nossa perspectiva, se apresenta como um espaço-tempo de disputas, de busca por exercício de poder e territorialização discursiva (MACEDO, 2006), que se materializa em textos, práticas, arranjos, entre outros.

O currículo configura-se como um campo de disputas a fim de legitimar visões específicas de mundo, mesmo que de forma provisória, se estabelecendo como uma arena política (SILVA, 1996), assim, um currículo formal pode ser entendido como o reflexo das visões de grupos dominantes. Com base em Santos e Meneses (2009), entendemos que o currículo é organizado e estruturado com base nos pressupostos da ciência moderna, a qual é resultado de uma intervenção colonialista epistemológica baseada na força, com características políticas, econômicas e militares atreladas ao capitalismo moderno imposto aos povos e culturas não ocidentais e não cristãos. Desse modo, utilizaremos também aportes das teorias póscoloniais e dos estudos decoloniais para identificar indícios de colonialidade, ou seja, identificar as experiências vivenciadas pelas nossas interlocutoras dentro dessa forma de conceber o conhecimento hegemônico como o natural.

\subsection{Breves apontamentos sobre colonialidade e decolonialidade nos estudos sobre currículo}

É importante elucidar que falar de colonialidade não significa que estamos falando de colonialismo. Segundo Castro-Gómez e Grosfoguel (2007), o colonialismo está relacionado a um contexto de ocupação territorial, enquanto a colonialidade se refere ao padrão de poder atual, caracterizado por uma hegemonia ocidental (colonialidade do poder), assim como uma 
epistemologia dominante na produção do conhecimento universal (colonialidade do saber). $\mathrm{O}$ fim do colonialismo não significou a destruição e a espoliação dos aspectos de dominação, mas sim o início de outro processo tortuoso, e inevitável, que se convencionou chamar de desenvolvimento e de modernização (CASTRO-GÓMEZ, 2005). Desde então, um imaginário colonial vem sendo reproduzido por boa parte das ciências sociais ao redor do mundo, e isso acontece também no Brasil.

Cabe aqui dizer que por meio das colonizações os europeus geraram uma nova perspectiva temporal da história e ressituaram os povos colonizados, bem como as suas perspectivas históricas e culturais, segundo as quais os povos colonizados sempre foram representados como "raças inferiores e - portanto - anteriores aos europeus" (QUIJANO, 2005, p. 238). Nesse movimento em que a Europa assume posição central em relação às outras partes do mundo, inaugura-se o que Santos (2007) chama de monocultura do tempo linear, estando embutidos conceitos de progresso, desenvolvimento e modernização em oposição ao simples, pré-moderno, primitivo e selvagem. No tempo linear, ou se está à dianteira (centro) ou se está aquém de seu objetivo (periferia).

Assim, entendemos que a dimensão epistemológica presente no currículo se traduz na permanência do colonizar, na medida em que é imposta uma única episteme, na qual os saberes locais, em muitos casos não escritos, mas orais - representados pelos conhecimentos, valores, crenças, costumes, atitudes, cosmovisão, organização do trabalho etc. - não entram na seleção, organização e materialização dos conteúdos escolares (MUNSBERG; FUCHS; SILVA, 2019),

Contrárias à monocultura do tempo linear, nas palavras de Castro-Gómez (2005), as teorias pós-coloniais demonstraram que qualquer narrativa da modernidade que não leve em conta o impacto da experiência colonial na formação das relações propriamente modernas de poder não é apenas incompleta, mas também ideológica. O pós-colonialismo refere-se a um discurso intelectual que reúne teorias ancoradas na filosofia, na ciência política e na literatura, com o foco em se constituir uma reação contra o legado colonial.

A teoria pós-colonialista tem como objetivo analisar o complexo das relações de poder entre as diferentes nações que compõem a herança econômica, política e cultural da conquista colonial europeia tal como se configura no presente momento - chamado, é claro, de póscolonial (SILVA, 2015). 
Apesar do importante movimento empreendido pelos(as) autores(as) pós-coloniais ${ }^{7}$ em refletir sobre a relação entre modernidade e colonialidade, muitos(as) deles(as) lançam mão de pensadores(as) ocidentais como principal instrumento teórico. Tal opção compromete a radicalidade da crítica ao eurocentrismo, a crítica feita à raiz da questão, uma vez que não rompe com padrões de pensamento constituídos. Assim, é importante frisar que as teorias póscoloniais e os estudos decoloniais se diferem principalmente em relação ao contexto histórico e à base teórica em que se fundamentam. Ballestrin (2013) discorre que, apesar dos estudos decoloniais diferenciarem-se das teorias pós-coloniais, ambos ainda mantêm boas relações entre seus pares.

De acordo com Grosfoguel (2010), a descolonização do conhecimento exigiria levar a sério a perspectiva/cosmologias/visões de pensadores(as) críticos(as) do Sul global, que pensam com e a partir de corpos e lugares étnico-raciais/sexuais subalternizados. Neste sentido, os(as) decoloniais buscam uma perspectiva que visa romper com os cânones ocidentais. Assim, esse pensamento pode ser entendido como uma chance de incorporar certa pluralidade de saberes e conhecimentos antes invisibilizados, já que questionam as relações de poder e as formas de conhecimento que privilegiam os padrões ocidentais, sobretudo o europeu, assim como permitem observar os processos de dominação e de resistência cultural.

Mesmo com o fim do colonialismo, alguns padrões de organização e comportamentos e alguns conceitos e categorias analíticas ainda hoje imperam como naturais, isto é, tornaram-se normas universais e se transformaram em modelo de civilização para todo o planeta. Entretanto, esse padrão parte de perspectivas hegemônicas da modernidade ocidental, que se pode chamar de colonialidade. Segundo Porto-Gonçalves (2005), essa colonialidade nos revela que há um legado epistemológico do eurocentrismo que nos impede de compreender o mundo a partir do próprio mundo em que vivemos e das epistemes que lhes são próprias. Para Maldonado-Torres (2007), a colonialidade não está limitada a uma relação formal de poder entre os povos ou nações, mas refere-se à forma como o trabalho, o conhecimento, a autoridade e as relações intersubjetivas se articulam através do mercado capitalista mundial e da ideia de raça. A colonialidade ainda hoje está presente nos manuais de aprendizagem, nos critérios para os trabalhos acadêmicos, na cultura, no senso comum, na autoimagem dos povos, nas aspirações dos sujeitos e em tantos outros aspectos de nossa experiência moderna. 
Por sua vez, o termo decolonialidade refere-se ao processo que busca transcender ou superar historicamente a colonialidade. De tal modo, Oliveira e Candau (2010) discutem que os estudos decoloniais derivam de uma perspectiva teórica em que autores(as) ${ }^{8}$ expressam as possibilidades de um pensamento crítico a partir do lugar de fala dos que foram subalternizados e da tentativa de construção de um pensamento crítico como força política para se contrapor às tendências acadêmicas dominantes de perspectiva eurocêntrica, que ainda hoje constroem o conhecimento histórico e social como sendo universal. Sendo assim, é possível considerar outras propostas educacionais experimentadas por práticas colaborativas, por ações mais horizontais e em perspectiva decolonial.

Para Walsh (2009, p.12), o pensamento decolonial pode ser uma alternativa à subalternização cultural e epistêmica das culturas não europeias, procurando desafiar e derrubar as estruturas sociais, políticas e epistêmicas da colonialidade, "estruturas essas permanentes que mantêm padrões de poder enraizados na racionalidade, no conhecimento eurocêntrico e na inferioridade de alguns seres humanos".

Tendo como aporte teórico essas vertentes, buscamos identificar os indícios de colonialidade presentes nos enunciados de nossas interlocutoras ao discutir sobre a Geografia escolar no contexto amazônico, questionando a importância da construção de pedagogias decoloniais para/na implementação da BNCC de Geografia. De acordo com Walsh (2013), as pedagogias decoloniais se apresentam como metodologias produzidas nos contextos de luta e resistência, ou seja, são pedagogias e práticas insurgentes que se opõem à modernidade/colonialidade e possibilitam muitas outras maneiras de ser, estar, pensar, saber, sentir existir e viver.

\section{INTERLOCUÇÕES SOBRE CURRÍCULO E A IMPLEMENTAÇÃO DA BNCC DE GEOGRAFIA NO CONTEXTO AMAZÔNICO: A BUSCA POR PEDAGOGIAS DECOLONIAIS}

Dentro do cenário pandêmico vivenciado no primeiro semestre de 2020, o Ciclo de Oficinas denominado "Interlocuções sobre currículo e a implementação da BNCC de Geografia", realizado como parte das ações do Projeto de Extensão "Interlocuções sobre a implementação da BNCC de Geografia: construindo práticas educativas regionais", foi realizado durante três encontros de forma remota por meio da plataforma Google Meet. Os 
encontros ocorreram nos dias 18 e 24 de junho e 02 de julho de 2020, das $19 \mathrm{~h}$ às $22 \mathrm{~h}$, quando foram abordados os seguintes temas: $1^{\circ}$ Encontro: Compreendendo o currículo escolar: histórico, conceitos e perspectivas; $2^{\circ}$ Encontro: Geografia escolar: currículo, representação e identidade; $3^{\circ}$ Encontro: BNCC de Geografia: mudanças, permanências e desafios. As inscrições estiveram disponíveis para estudantes da Universidade Federal do Tocantins (UFT), bem como para a comunidade em geral, na plataforma Serviços Integrados do Campus de Palmas (iServ/Sisma) e por meio de formulário eletrônico.

A escolha das temáticas de cada encontro esteve calcada no estabelecimento de múltiplas perspectivas a partir de contextos locais e de diferentes experiências. Com isso, o Ciclo de Oficinas teve como objetivo apresentar uma introdução ao entendimento sobre os estudos de currículo e sobre o contexto de produção, elaboração e implementação da BNCC, pretendendo, a partir do diálogo e da troca de saberes e experiências, contribuir para a formação (inicial e continuada) de professores(as) de Geografia, devido à percepção da urgência de se superar a colonialidade presente em documentos curriculares, com o intuito de suscitar uma proposta de pedagogia decolonial e intercultural para o contexto amazônico.

Buscamos, assim, refletir sobre a construção de conhecimento e intervenção na realidade tendo no horizonte o olhar direto e/ou a imersão nos contextos e modos de vida que resultam de processos de subalternização e exclusão histórica. Essa perspectiva pode nos ajudar a 'desaprender' (SPIVAK, 2010) determinadas versões dominantes do conhecimento e, com isso, resgatar, fortalecer e construir valores culturais, religiosos, sociais e educativos, como subsídios ao estímulo para um "outro" fazer pedagógico.

Tivemos a assiduidade de 17 (dezessete) participantes, além de outros 7 (sete) que conseguiram participar de apenas um dos encontros. Esse público foi composto por licenciandos(as) e docentes do curso de Geografia da UFT (campus-Araguaína), docentes da educação básica de Araguaína e de cidades da região central do estado do Tocantins, como Porto Nacional, além de docentes da região sul do estado do Maranhão.

Em um dos encontros, perguntamos "Qual sua compreensão sobre o currículo escolar de Geografia?", algumas das respostas foram: “levar o aluno a refletir sobre o mundo em que vive e a compreender o seu lugar no mundo", "compreender as transformações do pensamento geográfico no âmbito sociopolítico, econômico e cultural", "situar o estudante no seu papel geográfico e social", "direcionar o educador acerca dos conteúdos e práticas a serem 
Programa de Pós-Graduação em Educação: Currículo

desenvolvidas em sala", "O currículo com as transformações que ocorrem nos últimos anos, sair da decoreba, para ajudar o aluno a compreender o seu espaço com um olhar reflexivo e porventura, mais crítico".

Analisando essas respostas, podemos perceber que as visões acerca do currículo de Geografia se alinham à discussão que Straforini (2018) vem fazendo, de que a Geografia escolar é uma prática social composta por ideologias espaciais, já que os conteúdos presentes nos currículos dessa disciplina escolar, construídos por grupos que articulam a construção de imaginários sobre um território ou nação, têm potencial político que produz significados, identidades e disputas. Entretanto, pesquisas na área do Ensino de Geografia ${ }^{9}$ evidenciam que ainda hoje é comum encontrar práticas curriculares com metodologias de aprendizagem baseadas na memorização de conteúdos e conceitos que não acompanham as dinâmicas e complexas mudanças de nossa atual sociedade, isto é, trata-se de uma geografia conteudista e mnemônica desvinculada da vida dos alunos. Essa questão é evidenciada com a discussão trazida por umas das participantes, licencianda em Geografia e nascida na comunidade quilombola de Cocalinho, localizada no município de Santa Fé do Araguaia, região norte do Tocantins.

Na verdade, é uma colocação de experiências que eu vivi enquanto moradora de uma comunidade quilombola. Nos livros didáticos, o que o currículo coloca para nós é algo totalmente fora do nosso contexto enquanto comunidade quilombola, porque nós estudamos coisas sobre São Paulo. Vemos projeções cartográficas de outros países que são totalmente fora da nossa realidade. É lógico que isso é importante! Só que enquanto morador de lá (quilombo) nós não temos o incentivo de conhecermos a nossa própria comunidade, de conhecermos a nossa localidade. Isso no currículo não vem explícito (PARTICIPANTE A).

Durante os encontros, discutimos sobre o currículo numa perspectiva pós-crítica e pósestruturalista, considerando o currículo de Geografia um sistema de significação que, a partir de representações, age como um discurso de mundo (STRAFORINI, 2018). Dessa maneira, foi exposto um recorte do vídeo ${ }^{10}$ de uma palestra da nigeriana Chimamanda Adichie, no qual a escritora discorre sobre os estereótipos sociais e culturais construídos sobre o continente africano a partir da difusão de uma representação única da África e dos seus povos. Posteriormente, apresentamos um segundo vídeo ${ }^{11}$, um recorte da fala do historiador brasileiro Ailton Krenak, no qual discorre a respeito da história contada sobre a origem do Brasil como 
“descobrimento" constituir-se em uma invenção construída pelos portugueses e que é difundida até hoje nas escolas, portanto, é necessário contradizer essas ideias, contando outras narrativas, agora sob o ponto de vista dos povos indígenas. Entre a riqueza de diálogos proporcionada pela discussão da relação entre as temáticas dos vídeos e a implementação de documentos curriculares, como a BNCC, destacamos a experiência de uma licencianda em Geografia, já formada em História e professora dos anos iniciais do ensino fundamental, trazida para o debate:

\begin{abstract}
Aí fico me perguntando, fizeram tanta mudança e ainda vem o mito fundador [menção a obra de Marilena Chaú́] no livro didático já renovado pela BNCC. Então, eu vejo que eles tentaram disfarçar, "a relação do colonizador com o índio", entra com esse disfarce no livro. Mas ainda continua a questão de poder dos portugueses. Então, mudou-se muita coisa, criaram-se muita coisa, mas os livros didáticos ainda vêm com essas representações, que acaba que está a serviço de alguém, mas não é do povo, não é dessa identidade cultural de cada um. Aí eles trazem esse disfarce, "o olhar do céu sob a perspectiva indígena". Aí eles trazem esses nomes para dizer que estão nessas novas perspectivas, mas você vê que nos textos ainda tem muito do mito fundador presente (PARTICIPANTE B, 2020).
\end{abstract}

Como podemos observar nessa fala, é nítida a permanência ainda hoje de uma visão colonial em currículos descontextualizados e reprodutores de discursos eurocêntricos. Salientamos, assim, o papel da prática docente, que deve estar atenta para desmistificar discursos como esses presentes na realidade escolar. Nessa mesma direção, narrando sua experiência, destacamos os enunciados de uma graduanda em Geografia que reafirma a necessidade de discutirmos a descontextualização dos conteúdos curriculares:

Eu sou de Estreito, no Maranhão, e eu não tive educação sobre o Maranhão. O que eu sei é pouca coisa, é mais o que pesquisei depois que saí da escola. Então, na escola quase não tinha nada sobre o Maranhão. Eu lembro que tinha um livro fininho sobre a história do Maranhão, que falava sobre a política da família Sarney, sobre o coco babaçu, o Bumba meu boi, só que eu sou do Estreito, no sul do Maranhão. Então, além de ser pouco conteúdo sobre meu estado, ainda não me representava. Quando entrei para o ensino médio, estava ocorrendo na minha cidade uma grande problemática que era a construção da usina hidrelétrica, mas não se falava de usina hidrelétrica na minha escola, o máximo que acontecia era que iam engenheiros lá entregar panfletos falando como o CESTE [Consórcio Estreito Energia] ia mudar a cidade, trazer infraestrutura, como aquilo era o paraíso, mas não se falava sobre os povos que estavam sendo praticamente expulsos das suas terras, não se falava da problemática do rio, dos problemas que aquilo ia trazer para o rio, não se falava sobre o inchaço da cidade na época da construção, não se falava nada sobre isso. E eu só vim entender porque não se falava sobre isso e o que 
realmente aconteceu sobre as problemáticas da usina quando eu entrei na faculdade. Eu entrei na faculdade, e quem não entrou? E quem não teve oportunidade de estudar sobre isso? [...] Quando estava sendo tiradas as famílias para construção do lago, eu sei porque eu passava por ali, eu sabia quantas pessoas tinham sido realocadas, mas eu achava aquilo ali normal. Eu não entendia o que aquilo trazia para aquelas famílias, sobre o território, eu não entendia nada daquilo porque aquilo não foi me levado no ensino médio (PARTICIPANTE C, 2020).

Cabe à Geografia escolar fornecer aos processos de ensino-aprendizagem um saber estratégico para a compreensão do mundo atual sob os seguintes princípios do raciocínio geográfico: a analogia, a conexão, a diferenciação, a distribuição, a extensão, a localização e a ordem. Não cabendo a essa forma de raciocínio apenas a compreensão da realidade nas escalas dos grandes fenômenos e eventos, mas também a compreensão nas escalas regionais e locais, formando cidadãos capazes de refletir sobre e de questionar seu contexto e seu lugar no mundo. Ainda sobre essa discussão:

Eu tive uma professora de geografia que ela só me passava mapas, hoje eu sei localizar países e capitais no mapa porque eu só fiz isso. Então a gente estudava até sobre os outros estados, mas não estudava sobre o nosso estado. A gente não estudava sobre a nossa cidade que estava passando por um momento atípico com a construção da hidrelétrica. Então eu vim entender isso na faculdade, quando teve as primeiras palestras sobre a construção da usina. Aí eu me questionei, "nossa isso é um problema tão grande, por que eu não estudei sobre isso?". Como é importante essa representação, porque eu teria uma visão diferente e não teria tanta dificuldade na faculdade se eu tivesse estudado isso. Quando eu não estudava sobre o Maranhão no meu ensino fundamental eu pensava que era porque a escola não tinha um grande preparo e porque eu estudei a maior parte dele na zona rural, os primeiros anos do ensino fundamental foram precários. Eu estudava em escola de palha com vários alunos de várias séries juntos, então eu pensava que não tinha jeito uma escola que não tinha estrutura, nem merenda, nem banheiro, vai ter uma estrutura para se aprofundar nisso, vai ser estudado aquilo que está no livro didático. Mas hoje eu não entendo por que houve isso e por que ainda hoje há essa dificuldade de representação (PARTICIPANTE C, 2020).

Esses relatos das participantes a partir da realidade de sua prática docente e dos seus processos de escolarização salientam a necessidade de contextualização pelo docente dos currículos para/no contexto local/regional visando uma aprendizagem significativa para o estudante. A Geografa escolar só se faz essencial quando se apresenta como um instrumento contemporâneo, aproximando os alunos da sua realidade por meio de conteúdos geográficos que mostram como as relações entre fenômenos e eventos são históricas, dinâmicas e espacializadas. Contudo, a crítica à escola ou a prática docente por si só não contribui com a 
Programa de Pós-Graduação em Educação: Currículo

formação inicial e continuada de professores; em associação a isso, é essencial também a discussão sobre possibilidades de mudanças desse cenário ainda presente no contexto escolar. Assim, como exemplo de práticas pedagógicas contextualizadas, destacamos mais uma vez um relato da participante $\mathrm{B}$ :

O livro didático já está de acordo com a Base. Ele está com todos os objetivos da Base, com os códigos e tudo. E ele está trazendo no livro de Geografia do Ensino Fundamental I os espaços públicos e privados que são conteúdos dessas séries. Espaços públicos e privados, como se forma uma vila, como se forma uma cidade. E toda referência é do Rio de Janeiro. Então quando me deparo com esses conteúdos, porque mandaram mudarmos os conteúdos deste ano, tudo de acordo com a Base, aí eu me deparei com esse conteúdo e fiquei questionando com meus colegas. Eu não vou, meus alunos não precisam saber nesse momento como se formou Paraty (RJ). Eles precisam saber como se formou Araguaína. Então quais foram os espaços públicos que eu trouxe para eles? Eu trouxe o mesmo conteúdo, mas eu trouxe o Mercado Municipal, a Praça São Luiz Orione, a Praça das Bandeiras, quais são os espaços privados da cidade? Isso é só um exemplo que estou dando, que você pode pegar esse livro didático que está com esse conteúdo amarrado, com isso você esquematizar uma sequência didática para a sua realidade. E quando nos deparamos com o surgimento das vilas, de novo me deparei com os colonizadores portugueses, aí eu falei: - Não, espera aí! Então vamos fazer uma pesquisa com os alunos, com sua família, sobre como surgiu a cidade que eles nasceram, as cidades que eles vivem. Aí voltei para realidade dos alunos. Mas isso não é fácil, porque você tem que largar aquela referência e criar um projeto ou uma unidade didática ou uma sequência didática para que você consiga trabalhar aquele bimestre, aquele conteúdo, sem fugir daquele código, mas que você vai trazer a realidade dos alunos. Eu acho que faltam essas orientações na BNCC, de dizer, pega essas referências e adapta para a sua cidade, faça um projeto sobre a sua cidade, sobre os prefeitos, os vereadores da sua cidade. Vejam quais são os problemas do seu bairro. Esquece o bairro do Rio de Janeiro e veja quais os problemas do seu bairro (PARTICIPANTE $\mathrm{B}, 2020)$.

O compartilhamento de experiências como essas contribui com a formação docente dos(as) estudantes participantes e serve como inspiração para os professores já atuantes. Percebemos que a busca por repensar a prática pedagógica em uma perspectiva decolonial foi estabelecida com as ações do projeto de extensão por meio de reflexões, questionamentos e troca de experiências sobre possibilidades de fazeres curriculares contextualizados. Outro ponto importante que surgiu pelos(as) participantes no decorrer das oficinas foi sobre o papel da escola e do professor na manutenção de representações estereotipadas e mistificadas. $\mathrm{Ou}$, em um cenário igualmente desanimador, o da falta de representação local e/ou regional que se faça significante para os estudantes, como podemos observar fortemente nos relatos. Entendemos 
que a prática docente deve subverter essa lógica enraizada nos currículos, desvelando o máximo possível à sociedade e suas diversas manifestações de forma plural, contextualizada e intercultural.

Como apontado, as representações nos currículos são mecanismos poderosos para construção das múltiplas significações de Brasil, assim como de mundo, visto que vivemos em uma sociedade afetada por fluxos globais. Assim, é essencial às múltiplas representações sobre diferentes perspectivas. Fazendo um retrospecto do nosso próprio processo de escolarização, é possível identificar a frequência da reflexão "Por que devemos aprender tal assunto?", assim como do questionamento, "Os conteúdos estudados algum dia vão ser necessários para resolução ou reflexão de algum problema do cotidiano?”. É talvez nesse viés que, como professores e professoras, devemos repensar os currículos. No entanto, existem desafios impostos nas políticas educacionais e na gestão escolar que implicam diretamente no engessamento dos currículos e na falta de autonomia docente.

No Ciclo de Oficinas, valorizamos a contextualização da produção curricular como um mecanismo cíclico, disputado, ideológico e incerto, principalmente pensando as entrelinhas que não se fazem evidentes, mas que permeiam o contexto de produção da Base. É nesse sentido que cabe salientar que nesses encontros foi possível pensar diferentes caminhos para compreensão da BNCC, sendo um deles o de pensar a Base para além de uma visão restrita ao documento curricular oficial que está posto e deve ser seguido pelos docentes, mas sim, com uma visão de como é possível (re)significar essa proposta nos diferentes contextos da prática escolar.

\section{CONSIDERAÇÕES}

Compreendemos que a implementação de um currículo está articulada às diferentes escalas do sistema educacional, que vão desde os aspectos políticos mais amplos até as questões relativas aos conhecimentos e conteúdos disciplinares que serão ou não valorizados. Defendemos, apoiados em Goodson (1995) e Lopes e Macedo (2011), que a legitimação de um documento curricular pelo Estado não consegue controlar a prática docente na escola, sendo fundamental buscar compreender como a BNCC se estabelece e se organiza nos espaços 
escolares e como, nesse lócus de ação/interação, produzirá diversas contradições e formas "outras" de implementação que não foram estabelecidas no documento oficial.

Ademais, o currículo prescritivo é um mecanismo que disputa o controle das possibilidades de materialização curricular e que tem efeitos na escola e no trabalho docente, todavia, não consegue conter o que Oliveira (2003) define como currículos praticados, ou seja, os currículos que são construídos por meio das interações entre professor e estudante na prática escolar cotidiana, corporificando as propostas curriculares.

Com o propósito de contribuir para as discussões curriculares, indicamos que, à luz das pedagogias decoloniais, o currículo pode ser conduzido a novas representações, sentidos e saberes, procurando reivindicar múltiplas epistemologias na construção dos conhecimentos escolares. Como aponta Arroyo (2014), é possível romper com o silêncio historicamente imposto quando sujeitos dominados/subalternizados passam a interrogar as teorias educacionais. O questionamento contínuo às hegemonias epistemológicas mantidas pelos currículos pode culminar na construção de um novo marco que visa a constituição de outros lugares de fala na educação. É por meio dessa (re)existência no campo epistemológico, de silenciados a produtores de conhecimento, que os discursos, os conteúdos e as práticas curriculares presentes na BNCC podem ser confrontadas por diferentes cosmovisões.

Portanto, a riqueza das discussões estabelecidas pelas nossas interlocutoras foram os principais resultados adquiridos com essas ações de extensão. Vale ressaltar que a realização do Ciclo de Oficinas esteve centrada, ao longo dos encontros, na troca de conhecimentos e saberes entre os(as) participantes, ao invés de exposição de discussões teóricas. Ainda assim, percebemos que os embasamentos teóricos apresentados representaram um dos passos importantes para se pensar o currículo e a implementação da BNCC de Geografia.

\section{REFERÊNCIAS}

AGB. Associação dos Geógrafos Brasileiros. Dialogar e resistir: porque dizemos não à nova Base Nacional Comum Curricular. 2017. Disponível em: hhttp://files.agbbelohorizonte.webnode.com.br/200000459-cbeafcce42/DIALOGARERESISTIR.pdf. Acesso em: 04 jan. 2020.

AGUIAR, Márcia Angela da Silva; DOURADO, Luiz Fernandes (Org.). A BNCC na contramão do PNE 2014-2024: avaliação e perspectivas. [S.1.]: ANPAE, 2018. Livro Eletrônico. 
ARROYO, Miguel. Outros Sujeitos, Outras Pedagogias. Petrópolis, RJ: Vozes, 2014.

BALLESTRIN, Luciana. América Latina e o giro decolonial. Revista Brasileira de Ciência Política. n. 11, p. 89-117, 2013. Disponível em: https://www.scielo.br/pdf/rbcpol/n11/04.pdf. Acesso em: 10 ago. 2020.

BARBOSA, Alessandro Tomaz; DINIZ, Vanessa Lessio; PAULINO, Vicente. Currículo, cultura e educação em Timor-Leste: conflitos e resistências entre o local e o global. In: BARBOSA, Alessandro Tomaz; DINIZ, Vanessa Lessio; PAULINO, Vicente. Currículo e Educação: Timor-Leste em Destaque. Díli: Unidade de Produção e Disseminação do Conhecimento Programa de Pós-Graduação e Pesquisa da UNTL, 2020. p. 13-17.

BRASIL. Constituição. Constituição da República Federativa do Brasil. Brasília, DF: Senado Federal: Centro Gráfico, 1988.

BRASIL. LDB: Lei de diretrizes e bases da educação nacional. Brasília: Senado Federal, Coordenação de Edições Técnicas, 2017.

BRASIL. Ministério da Educação. Base Nacional Comum Curricular. 2018. Disponível em:

http://basenacionalcomum.mec.gov.br/images/BNCC_EI_EF_110518_versaofinal_site.pdf. Acesso em: 04 jan. 2020.

CASTRO-GÓMEZ, Santiago. La poscolonialidadexplicada a los niños. Cauca: Editorial Universidad del Cauca - Instituto Pensar, Universidad Javeriana, 2005.

CASTRO-GÓMEZ, Santiago; GROSFOGUEL, Ramóm (Orgs.) El giro decolonial: reflexiones para una diversidad epistémica más allá del capitalismo global. Bogotá: Siglo del Hombre Editores, 2007.

CAVALCANTI, Lana de Souza. O Ensino de Geografa na Escola. Campinas: Papirus, 2013.

COSTA, Hugo Heleno Camilo; PEREIRA, Talita Vidal. Sentidos de Interdisciplinaridade articulados nas políticas de currículo: o caso das disciplinas. Ciências Naturais e Geografia. Cadernos de Educação. FaE/PPGE/UFPel. Pelotas [44]: 293 - 318, janeiro/abril 2013. Disponível em: https://periodicos.ufpel.edu.br/ojs2/index.php/caduc/article/view/2749. Acesso em: 10 ago. 2020.

CURY, Carlos Roberto Jamil; REIS, Magali; ZANARDI, Teodoro Adriano Costa. Base Nacional Comum Curricular: dilemas e perspectivas. São Paulo: Cortez, 2018.

ESCOBAR, Arturo. Mundos y conocimientos de otro modo. Disponível em: www.decoloniality.net/files/escobar-tabula-rasa.pdf. Acesso em: 10 ago.2020. 
GIROTTO, Eduardo Donizeti. Dos PCNs à BNCC: o ensino de geografia sob o domínio neoliberal. GEO UERJ, v. 1, p. 419-439, 2017. Disponível em: https://www.epublicacoes.uerj.br/index.php/geouerj/article/view/23781/21158. Acesso em: 04 jan. 2020.

GOODSON, Ivor. Currículo: Teoria e História. Petrópolis, Rio de Janeiro: Vozes, 1995.

GROSFOGUEL, Ramóm. Para descolonizar os estudos de economia política e os estudos pós-coloniais: transmodernidade, pensamento de fronteira e colonialidade global. In:

SANTOS, Boaventura de S. MENESES, Maria P. (Orgs.) Epistemologias do Sul. São Paulo: Cortez, 2010. p. 383-417.

LACLAU, Ernesto. Emancipação e Diferença. Coordenação e revisão técnica geral: Alice Casimiro Lopes e Elizabeth Macedo. Rio de Janeiro: EdUERJ, 2011.

LACLAU, Ernesto; MOUFFE, Chantal. Hegemonia e estratégia socialista: por uma política democrática radical. Tradução: Joanildo Burity, Josias de Paula Jr. e Aécio Amaral. São Paulo: Intermeios; Brasília: CNPq, 2015.

LOPES, Alice Casimiro. Políticas de Currículo: questões teórico-metodológicas. In: LOPES, Alice Casimiro; DIAS, Rosanne. Evangelista; ABREU, Rozana. Gomes de (Orgs.). Discursos nas políticas de currículo. Rio de Janeiro: Quartet, 2011. p. 19-47.

LOPES, Alice Casimiro; MACEDO, Elisabete. Teorias de Currículo. São Paulo: Cortez, 2011.

LOPES, Alice Casimiro. Apostando na Produção Contextual do Currículo. In: AGUIAR, Márcia Angela; DOURADO, Luiz Fernandes (Orgs.). A BNCC na contramão do PNE 2014-2024: avaliação e perspectivas. [S.1.]: ANPAE, 2018. p. 23-27.

MACEDO, Elizabeth. Currículo como espaço-tempo de fronteira cultural. Revista Brasileira de Educação. São Paulo, n. 32, v. 11, maio-ago. ANPED, 2006. Disponível em: https://www.scielo.br/pdf/rbedu/v11n32/a07v11n32.pdf. Acesso em: 10 ago. 2020.

MACEDO, Elizabeth. Base nacional comum para currículos: direitos de aprendizagem e desenvolvimento para quem? Revista Educação \& Sociedade, Campinas, v. 36, nº133, p.891-908, out-dez, 2015. Disponível em: https://www.scielo.br/pdf/es/v36n133/1678-4626es-36-133-00891.pdf. Acesso em: 10 ago. 2020.

MALDONADO-TORRES, Nelson. Sobre la colonialidad del ser: contribuciones al desarrollo de um concepto. In: CASTRO-GÓMEZ, Santiago; GROSFOGUEL, Ramón (Orgs.). El giro decolonial: Reflexiones para una diversidad epistémica más allá del capitalismo global. Bogotá, 2007. p. 127-167.

MENDONÇA, Daniel; RODRIGUES, Léo Peixoto. Em torno de Ernesto Laclau: pósestruturalismo e teoria do discurso. In: MENDONÇA, Daniel.; RODRIGUES, Léo. 
Peixoto. (Orgs.) Pós-estruturalismo e teoria do discurso: Em torno de Ernesto Laclau. 2. ed. Porto Alegre: EDIPUCRS, 2014. p. 27-45.

MUNSBERG, João Alberto Steffen; FUCHS, Henri Luiz; SILVA, Gilberto Ferreira. O currículo decolonial: da reflexão à colaboração intercultural. Revista Gestão Universitária, 2019. Disponível em: http://gestaouniversitaria.com.br/artigos/o-curriculo-decolonial-dareflexao-a-colaboracao-intercultural. Acesso em: 10 ago. 2020.

OLIVEIRA, Luiz Fernandes de.; CANDAU, Vera Maria Ferrão. Pedagogia decolonial e educação antirracista e intercultural no Brasil. Educação em Revista. v. 26, n. 01. Belo Horizonte, 2010. Disponível em: https://www.scielo.br/pdf/edur/v26n1/02.pdf. Acesso em: 10 ago. 2020.

OLIVEIRA, Inês Barbosa. Currículos praticados: entre a regulação e a emancipação. Rio de Janeiro: DP\&A, 2003.

PEREIRA, Carolina Machado Rocha Busch. Leitura Crítica. Base Nacional Comum Curricular - BNCC - $3^{\text {a }}$ versão. Ensino Fundamental - Geografia. Ministério da Educação. 2017. Disponível em: http://basenacionalcomum.mec.gov.br/images/relatoriosanaliticos/Parecer_9_GE_Carolina_Machado_Rocha_Busch_Pereira.pdf. Acesso em: 10 ago. 2020.

PORTO-GONÇALVES, Carlos Walter. Apresentação da edição em português. In: LANDER, Edgardo (Org.). A Colonialidade do Saber: Eurocentrismo e Ciencias Sociais. Perspectivas Latinoamericanas. Buenos Aires, 2000. p. 03-05.

PPC. Projeto Pedagógico do Curso de Geografia - Licenciatura (Campus-Araguaína). Universidade Federal do Tocantins. Pró-Reitoria de Graduação, 2019.

QUIJANO, Aníbal. Colonialidade do poder, Eurocentrismo e América Latina. CLACSO, Consejo Latino-americano de Ciencias Sociales. Buenos Aires, 2005.

SANTOS, Boaventura de Sousa. Renovar a teoria crítica e reinventar a emancipação social. São Paulo: Boitempo, 2007.

SANTOS, Boaventura de Sousa; MENESES, Maria Paula. Introdução. In: SANTOS, Boaventura de Sousa; MENESES, Maria Paula (Orgs.). Epistemologias do sul. Coimbra: Edições Almedina, 2009. p. 9-19.

SILVA, Tomaz Tadeu da. Identidades Terminais: as transformações na política da pedagogia e na pedagogia da política. Petrópolis: Vozes, 1996.

SILVA, Tomaz Tadeu da. Documentos de identidade: uma introdução às teorias de currículo. Belo Horizonte: Autêntica, 2015. 
SPIVAK, Gayatri Chakravorty. Pode o subalterno falar? Belo Horizonte: Editora UFMG, 2010.

STRAFORINI, Rafael. Ensinar Geografia: o desafio da totalidade-mundo nas series iniciais. 2. ed. São Paulo: Annablume, 2008.

STRAFORINI, Rafael. Permanências e mudanças no currículo de geografia dos anos iniciais ensino fundamental. Revista Brasileira de Educação em Geografia, Campinas, v. 6, n. 11, p.160-184, jan. /jun., 2016. Disponível em: https://www.revistaedugeo.com.br/ojs/index.php/revistaedugeo/article/view/377. Acesso em: 04 jan. 2020.

STRAFORINI, Rafael. O ensino de Geografia como prática espacial de significação. Revista Estudos Avançados. n³2 (93), 2018. Disponível em: http://www.revistas.usp.br/eav/article/view/152621. Acesso em: 10 ago. 2020.

VALLADARES, Marisa Terezinha Rosa et al. Contexto da construção da primeira e segunda versões da Base Nacional Comum Curricular no componente curricular de geografia. Revista de Geografia do Colégio Pedro II, v. 3, n. 6, p. 7-18, 2016. Disponível em: https://www.cp2.g12.br/ojs/index.php/GIRAMUNDO/article/view/1661. Acesso em: 04 jan. 2020.

WALSH, Catherine. Interculturalidad, Estado, Sociedad: Luchas (de)coloniales de nuestra época. Universidad Andina Simón Bolivar, Ediciones Abya-Yala: Quito, 2009.

WALSH, Catherine. Pedagogías Decoloniales: prácticas insurgentes de resistir, (re)existir y (re)vivir. Equador: Abya Yala, 2013.

\section{NOTAS}

${ }^{1}$ Disponível em: http://basenacionalcomum.mec.gov.br/historico.

${ }^{2} \mathrm{O}$ Tocantins está inserido na área da Amazônia Legal, caracterizando-se como um estado multicultural. De acordo com o Projeto Pedagógico do Curso de Geografia (UFT/Araguaína, 2019), as diversas formas de territorialidades no Tocantins merecem ser conhecidas, já que a ocupação do estado se dá pelos indígenas, pelos afro-descendentes, entre outros grupos. Os estudos realizados na UFT revelam as múltiplas identidades e as diversas manifestações culturais presentes na realidade desse estado, bem como as questões da territorialidade como princípios de um ideal de integração e desenvolvimento local.

${ }^{3} \mathrm{O}$ presente projeto de extensão está inserido no edital PROEX/UFT N ${ }^{\circ}$ 01/2020 da Pró-Reitoria de Extensão, Cultura e Assuntos Comunitários (PROEX), sendo desenvolvido com o apoio do Programa Institucional de Bolsas de Extensão da Universidade Federal do Tocantins (PIBEX) com bolsa concedida pelo edital PROEX/UFT N ${ }^{\circ}$ $07 / 2020$

${ }^{4}$ As principais categorias analíticas da Teoria de Discurso são exploradas no livro "Emancipação e Diferença" (LACLAU, 2011, p. 47-105).

5 "A política curricular pode ser pensada como produção discursiva, performada no confronto contaminante de diferentes discursos sociais que, duplamente, reiteram e traem os sentidos trazidos à baila, recriando-os por tradução. Tal reapropriação do outro é a marca do currículo como produção cultural, como fronteira espaçotemporal de negociação com a diferença que leio" (COSTA; PEREIRA, 2013, p. 35). 
Programa de Pós-Graduação em Educação: Currículo

6 “Tal concepção de discurso retira da hegemonia o sentido de algo imutável, incontestável e intransponível uma vez fixado. Assim, um dado sentido discursivo curricular só é permanência - entendida aqui como um discurso hegemônico - em um tempo " $x$ " enquanto outros discursos ou pautas exteriores permanecerem contrárias ou dissonantes a ele, ou seja, o que se revela como discursos de mudança e de permanência são identidades discursivas próprias ou particulares e pouco conciliáveis. Contraditoriamente, havendo um ponto em comum entre ambos os discursos, em que sentidos discursivos exteriores e os interiores se juntam numa cadeia de equivalência, é que a mudança curricular enquanto uma prática curricular pode ocorrer efetivamente e, consequentemente, um novo discurso hegemônico tende a se instalar" (STRAFORINI, 2016, p. 169).

${ }^{7}$ Frantz Fanon, Albert Memmi, Aimé Césaire são alguns dos principais referenciais da perspectiva pós-colonial. Entretanto, também se pode somar a esse grupo de intelectuais os autores: Edward Said, Gayatri Spivak e Homi Bhabha.

8 Esses autores são denominados por Arturo Escobar (2003) pesquisadores da perspectiva teórica "Modernidade/Colonialidade", sendo eles: Enrique Dussel, Aníbal Quijano, Walter Mignolo, Santiago CastroGómez, Ramón Grosfoguel, Catherine Walsh, Nelson Maldonado-Torres, o próprio Arturo Escobar, entre outros. Já Boaventura de Souza Santos e Maria Paula Meneses (2009) desenvolvem pesquisas com uma abordagem que busca a construção de uma epistemologia que parta do Sul global.

${ }^{9}$ STRAFORINI (2008) e CAVALCANTI (2013) são alguns trabalhos que abordam essa temática.

${ }^{10}$ Disponível em: https://www.youtube.com/watch?v=EC-bh1YARsc.

${ }^{11}$ Disponível em: https://www.youtube.com/watch?v=VeMlSgnVDZ4.

Recebido em: 29/08/2020

Aprovado em: 03/12/2020 